\title{
Obstetric and neonatal outcome in pregnancies complicated by hemolysis elevated liver enzymes low platelet count syndrome at a tertiary care centre in India
}

\author{
Nidhi O. Bang*, Meena N. Satia, Supriya Poonia
}

\begin{abstract}
Department of Obstetrics and Gynaecology, Seth Gordhandas Sunderdas Medical College and King Edward VII
\end{abstract} Memorial Hospital, Mumbai, Maharashtra, India

Received: 27 May 2016

Accepted: 17 June 2016

\author{
*Correspondence: \\ Dr. Nidhi O. Bang, \\ E-mail: nidhibang8@gmail.com
}

Copyright: () the author(s), publisher and licensee Medip Academy. This is an open-access article distributed under the terms of the Creative Commons Attribution Non-Commercial License, which permits unrestricted non-commercial use, distribution, and reproduction in any medium, provided the original work is properly cited.

\begin{abstract}
Background: The hemolysis elevated liver enzymes low platelet count (HELLP) syndrome is a serious complication in pregnancy characterized by hemolysis, elevated liver enzymes and low platelet count occurring in 0.4 to $0.7 \%$ of all pregnancies and in 10-12\% of cases with severe preeclampsia. This present study will throw some light on occurrence, diagnosis, complications, treatment, mode of delivery and the neonatal outcome.

Methods: A prospective observational study was conducted in the department of Obstetrics and Gynecology at Seth G.S. Medical College and KEM hospital which is a tertiary care centre in Mumbai in the state of Maharashtra India from September 2013 to December 2014 after the approval of institutional ethics committee. The inclusion criteria were only those patients in whom HELLP syndrome was diagnosed on the basis of blood investigations, laboratory parameters and clinical picture. All those patients who did not fulfill the diagnostic criteria for HELLP syndrome were excluded.

Results: In our study, according to the Mississippi classification, $15 \%$ belonged to class 1, 62\% to class 2 and $23 \%$ to class 3. The peak age of incidence was 21-30 years (78\%) and majority were primigravida (57\%). Majority (91\%) presented with headache and the other associated complains were epigastric pain, nausea, vomiting and blurring of vision. Only $32 \%$ patients presented at term (>37 weeks), $65 \%$ patients were at $28-36$ weeks of gestation and $3 \%$ had very early onset HELLP syndrome. Majority (65\%) had severe hypertension (BP>160/110 $\mathrm{mm}$ of $\mathrm{Hg}$ ) with albuminuria of grade +3 to +4 . Majority $(83 \%)$ of the patients were given injection $\mathrm{MgSO} 4$ either for prophylaxis or treatment of eclampsia. $65 \%$ patients delivered vaginally. $70 \%$ were live births, out of which $8 \%$ died in the early neonatal period. Severe maternal complications such as eclampsia, hematuria, acute kidney injury, abruption placentae, severe anemia and DIC were seen in $63 \%$ patients. $57 \%$ of patients were transfused with blood and blood products and $7 \%$ required intensive care management.

Conclusions: A multidisciplinary approach is of utmost importance along with early diagnosis and prompt treatment to prevent the cataclysmic deterioration of patients with HELLP syndrome.
\end{abstract}

Keywords: HELLP syndrome, Pre-eclampsia, Hemolysis

\section{INTRODUCTION}

HELLP syndrome is a serious complication in pregnancy which may threaten the woman's life and is considered as a variant of pre-eclampsia. HELLP was once named as edema-proteinuria-hypertension gestosis type $\mathrm{B}$ by Goodlin et al in the early $20^{\text {th }}$ century and was later renamed in 1982 by Weinstein L as HELLP syndrome. It is an acronym used to describe the condition of a patient with severe pre-eclampsia or eclampsia who occurs in 5$10 \%$ of pregnancies. ${ }^{1,2}$ It is best described as a pregnancy-specific syndrome that can affect virtually every organ system. It may result in various maternal complications such as eclampsia, cerebrovascular 
accident, placental abruption, pulmonary edema, acute renal failure, microangiopathic hemolytic anemia and HELLP syndrome.

HELLP syndrome develops in 6-12\% of women with preeclampsia or eclampsia accounting for $0.4-0.7 \%$ of all pregnancies. $^{3} \quad$ Clinical features and laboratory abnormalities define and determine the severity of HELLP syndrome. It typically occurs after 28 weeks of gestation up to delivery or immediately postpartum in 15$30 \%$ of cases. The presentation of patients with HELLP syndrome is variable. The patients may have symptoms from flu like illness to gastrointestinal hemorrhage. ${ }^{4} 90 \%$ of patients experience malaise, fatigue, and nonspecific complaints for a few days before seeking medical evaluation. Half of all patients report nausea and vomiting and or headache, whereas the ominous symptom of epigastric or right upper quadrant pain is present only in half to two thirds of patients. ${ }^{5-7}$ With a hepatic haemorrhage, the patient may complain of neck and shoulder pain.

The clinical signs largely depend on the underlying organ system involved. The physical examination may be normal in patients with HELLP syndrome. Tenderness in right upper quadrant of abdomen is present in as many as $90 \%$ of patients. Icterus may be present in patients with HELLP syndrome who complain of severe pain in the right upper quadrant of abdomen, neck pain or shoulder pain and should be considered for hepatic imaging regardless of the severity of laboratory abnormalities and assessed for sub capsular hematoma or hepatic rupture. Weight gain and edema are usual physical findings.

Blood pressure is elevated to the severe range (systolic $>=160 \mathrm{mmHg}$ or diastolic $>=110 \mathrm{mmHg}$ ) in two third patients with HELLP syndrome. Proteinuria is present to the level of $>=2+$ on dipstick in $85 \%$ of patients, minimal proteinuria (1+) in $9 \%$ and absent in $6 \%$.

Pre-eclampsia, eclampsia and HELLP syndrome were traditionally described as the disease of unknown etiology. HELLP syndrome seems to be the final manifestation of some insult that leads to microvascular endothelial damage and intravascular platelet activation with release of thromboxane A2 and serotonin causing vasospasm, platelet agglutination and aggregation and further endothelial damage. Thus begins a cascade that is terminated only with delivery.

Classification system has been formulated to enable physicians to identify patients at risk, to guide therapeutic interventions and to provide a common platform for comparison of research results. It can be classified according to Mississippi classification based on maternal platelet count, liver transaminases and lactate dehydrogenase into class 1, 2 and 3.

Once diagnosed, decision should be made regarding delivery. Due to progressive nature of the disease, these patients should always be hospitalized with vigilant care in labour and delivery. The assessment of maternal condition is of utmost importance by history taking, clinical examination and blood investigation parameters. Hypertension should be controlled and decision should be made regarding the need of injection magnesium sulphate and transfusion of blood and blood products. Women with worsening parameters of HELLP syndrome are at increased risk of maternal morbidity and mortality. One has to be vigilant against development of multi organ system failure. It may progressively involve various systems and result in to eclampsia, acute renal failure, DIC, severe anemia, liver rupture and intra cerebral haemorrhage. The intravascular volume, fluid and electrolyte balance has to be maintained. It's seen that corticosteroids in high doses expedite the improvement in laboratory parameters and thereby reduces hospital stay and adverse maternal complications.

Fetal surveillance is done by ultrasonography, Non stress test and doppler studies. Corticosteroids are given for fetal lung maturity in cases of anticipated preterm delivery.

Maternal and fetal condition, gestational age, bishops score, inducibility of the cervix are the few factors which helps in deciding over the mode of delivery.

Hence, multidisciplinary management, involving an obstetrician, anaesthetist, physician and a neonatologist, is carried out with consideration of the maternal risks due to continued pregnancy and the fetal risk associated with induced preterm delivery. Screening women at high risk and preventing recurrences are therefore the key issues in management. Early diagnosis and identification of complications of HELLP syndrome and timely intervention forms the main strategy of treatment. ${ }^{8}$

With this background, this study has therefore been carried out to throw some light on the pregnancies complicated by HELLP syndrome and to emphasize upon early diagnosis and management to improve maternal and fetal outcome.

\section{METHODS}

A prospective observational study was conducted in the department of Obstetrics and Gynecology at Seth G.S. Medical College and KEM Hospital which is a tertiary care centre from September 2013 to December 2014 after the approval of institutional ethics committee.

A detailed history was taken and thorough clinical examination done of all the antenatal patients. All the patients who were diagnosed as HELLP syndrome on the basis of clinical picture and blood investigations such as platelet count, SGOT, SGPT, bilirubin, LDH, hemoglobin and peripheral smear were included in the study. All classes of HELLP syndrome were included. 
All patients of HELLP irrespective of their registration status and parity status were included in the study.

All pregnancies with gestational hypertension or preeclampsia, but laboratory parameters not diagnostic of HELLP were excluded from the study. Also patients unwilling to give informed consent were excluded.

The maternal outcome was noted in terms of the gestational age, mode of delivery, clinical features, maternal complications and the need of transfusion of blood and blood products. Neonatal outcome in terms of morbidity and mortality and need of NICU admission was noted.

The data obtained has been systematically tabulated and analyzed using Excel and SPSS software packages. The results were averaged for each parameter for continuous data and number and percentage for categorical values are presented in tables.

\section{RESULTS}

60 patients were diagnosed of HELLP syndrome on the basis of the clinical profile and laboratory parameters. In our study, we thoroughly studied the signs, symptoms, complications and the events of labour and followed up the patients till recovery and discharge.

Table 1: Demographic profile of the patients $(n=60)$.

\begin{tabular}{|lll|}
\hline Age in years & Number & Percentage \\
\hline$<25$ years & 27 & $45 \%$ \\
\hline 26-30 years & 20 & $33.3 \%$ \\
\hline$>30$ years & 17 & $21.67 \%$ \\
\hline Registeration status & & \\
\hline Yes & 9 & $15 \%$ \\
\hline No & 51 & $85 \%$ \\
\hline Gravida status & & \\
\hline Primigravida & 34 & $57 \%$ \\
\hline Multigravida & 26 & $43 \%$ \\
\hline
\end{tabular}

The peak incidence of HELLP syndrome was seen in the age group of less than 30 years $(85 \%)$. Most of the patients $(85 \%)$ were transferred to the tertiary care centre from peripheral heath care centres and rural areas; whereas only $15 \%$ were antenataly registered with us. $57 \%$ of them were primigravida, whereas a significant number $(43 \%)$ was that of multigravida patients.

According to the Mississippi classification majority of the patients $(62 \%)$ belonged to class 2 , whereas only $15 \%$ belonged to the most severe form that is class 1 with platelet count of $<50000 / \mathrm{ml}$. Majority of the patients presented with headache, severe hypertension and albuminuria. Other associated symptoms were epigastric pain, nausea, vomiting and blurring of vision. Injection $\mathrm{MgSO} 4$ was given to $83 \%$ of the patients either for the treatment or prevention of seizures.
Table 2: Classification of HELLP syndrome and clinical profile of the patients.

\begin{tabular}{|lll|}
\hline $\begin{array}{l}\text { Mississippi classification } \\
\text { Class1 (platelet count }\end{array}$ & $\begin{array}{l}\text { Number } \\
(\mathbf{n = 6 0})\end{array}$ & Percentage \\
$\begin{array}{l}<50,000 / \mathrm{ml}) \\
\text { Class2 (platelet count } \\
50,000-1,00,000 / \mathrm{ml})\end{array}$ & 37 & $62 \%$ \\
\hline $\begin{array}{l}\text { Class3 (platelet count } \\
1,00,000-1,50,000 / \mathrm{ml})\end{array}$ & 14 & $23 \%$ \\
\hline Clinical profile & & \\
\hline Headache & 55 & $91.67 \%$ \\
\hline Epigastric pain & 33 & $55 \%$ \\
\hline Nausea or vomiting & 23 & $38.33 \%$ \\
\hline Blurring of vision & 15 & $25 \%$ \\
\hline Severe hypertension & 39 & $65 \%$ \\
\hline Albuminuria grade +3 to +4 & 41 & $68.3 \%$ \\
\hline $\begin{array}{l}\text { Injection magnesium } \\
\text { sulphate }\end{array}$ & 50 & $83.3 \%$ \\
\hline
\end{tabular}

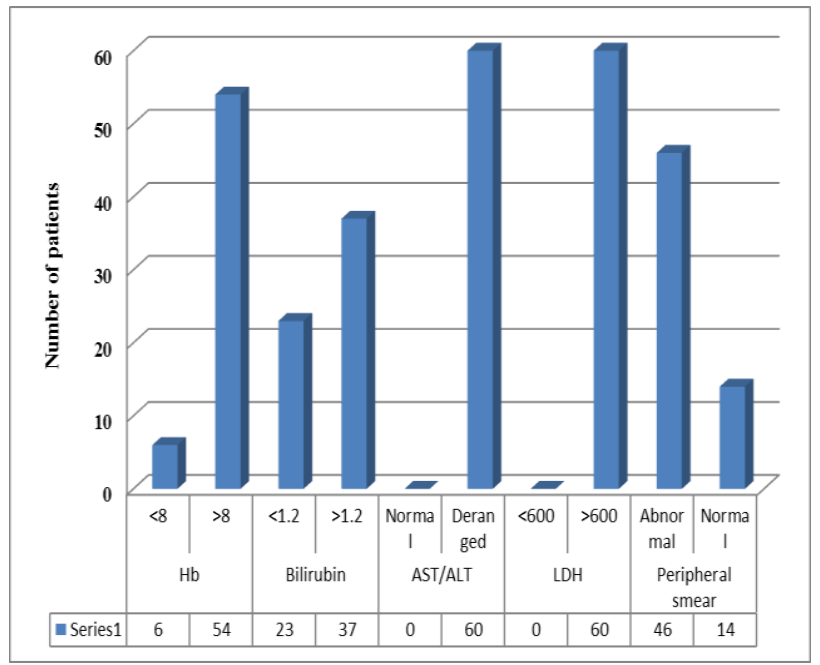

Figure 1: Laboratory parameters.

Table 3: Maternal complications in the cases of HELLP syndrome.

\begin{tabular}{|lll|}
\hline Maternal complications & Number & Percentage \\
\hline Abruptio placentae & 6 & $10.00 \%$ \\
\hline Acute kidney injury(AKI) & 4 & $6.67 \%$ \\
\hline Eclampsia & 14 & $23.33 \%$ \\
\hline DIC & 2 & $3.34 \%$ \\
\hline Hematuria & 9 & $15.00 \%$ \\
\hline Severe anaemia & 2 & $3.33 \%$ \\
\hline Status eclampticus & 1 & $1.67 \%$ \\
\hline No complications & 22 & $36.67 \%$ \\
\hline Total & $\mathbf{6 0}$ & $\mathbf{1 0 0 . 0 0 \%}$ \\
\hline
\end{tabular}

As we have already discussed, HELLP is an acronym which stands for haemolysis, elevated liver enzymes and low platelet count. Haemolysis is confirmed by anemia, raised bilirubin levels or abnormal peripheral smear. As 
shown in Figure 1, $10 \%$ (6) patients had $\mathrm{Hb}<8 \mathrm{gm} \%$. $61 \%$ (37) patients had serum bilirubin $>1.2 \mathrm{mg} / \mathrm{dl}$ and $76 \%$ (46) patients had abnormal peripheral smear showing schistocytes or echinocytes. All the patients had AST/ALT $>70 \mathrm{IU} / \mathrm{L}$ and $\mathrm{LDH}>600$. All the patients had platelet count less than $1,50,000 / \mathrm{ml}$, the severity of which classified them into different classes.

Majority of the patients $(63.3 \%)$ patients had complications associated with HELLP syndrome. Eclampsia was the most common seen in $23 \%$ of cases, followed by haematuria, abruption placentae and acute kidney injury. Other associated complications were severe anemia, disseminated intravascular coagulation (DIC) and status eclampticus. Out of which $7 \%$ patients were shifted to MICU for intensive care.

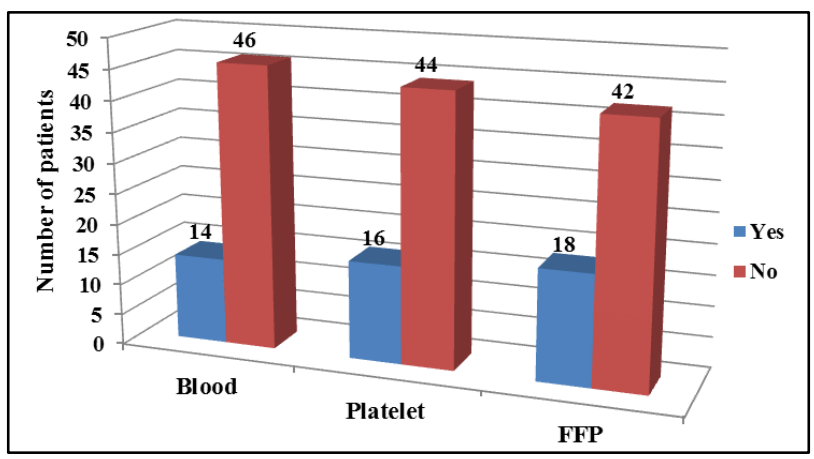

Figure 2: Transfusion of blood and blood products.

Majority of the patients were transfused with blood and blood products depending upon their laboratory parameters. As shown in Figure 2, 30\% patients were transfused with FFP, $26 \%$ with platelets and $23 \%$ with blood.

Table 4: Gestational age and mode of delivery.

\begin{tabular}{|lll|}
\hline Gestational age & Number $(\mathbf{n = 6 0})$ & Percentage \\
\hline$<28$ weeks & 2 & $3 \%$ \\
\hline $28-32$ weeks & 11 & $18 \%$ \\
\hline $32-36$ weeks & 28 & $47 \%$ \\
\hline$>37$ weeks & 19 & $32 \%$ \\
\hline Mode of delivery & & \\
\hline Vaginal delivery & 39 & $65 \%$ \\
\hline LSCS & 21 & $35 \%$ \\
\hline
\end{tabular}

Table 5: Neonatal outcome.

\begin{tabular}{|lll|}
\hline Neonatal outcome & Number $(\mathbf{n = 6 0})$ & percentage \\
\hline Live births & 42 & $70 \%$ \\
\hline IUFD & 7 & $11.7 \%$ \\
\hline FSB & 11 & $18.3 \%$ \\
\hline NICU admission & 22 & $36.6 \%$ \\
\hline Early neonatal deaths & 5 & $8.3 \%$ \\
\hline
\end{tabular}

Majority of the patients $(68 \%)$ delivered pre term. They were either induced for vaginal delivery or underwent caesarean section for various obstetric indications before 37 weeks as delivery forms the mainstay of management in cases of HELLP syndrome. The underlying catastrophic pathological events come to an end only with the delivery of fetus and placenta. A very early onset HELLP (<28 weeks) was seen only in $3 \%$ of the cases. Most of the patients $(65 \%)$ had vaginal delivery whereas $35 \%$ underwent caesarean section.

As shown in Table 5, of all patients, $70 \%$ had live births out of which $36 \%$ required NICU admission. $8 \%$ babies died in the early neonatal period. $18.3 \%$ were still born and around $12 \%$ were diagnosed as intrauterine fetal demise (IUFD) before contemplating labour.

\section{DISCUSSION}

It has been widely accepted that standard antenatal care has immense values in reducing the incidence of HELLP syndrome by early detection of pre-eclampsia and its prompt management. Pre-eclampsia presenting with atypical clinical presentation is well known since the end of $19^{\text {th }}$ Century. Dieckmenn called this spectrum the toxaemia of pregnancy. Dieckmenn in 1941 titled his classic textbook about preeclampsia- 'the toxaemia of pregnancy' where he mentioned this complicated clinical presentation in patients with preeclampsia. ${ }^{11}$ In early 1980 Weinstein L, had a terrible personal impact after encountering his first maternal death who presented with varied pre-eclampsia. He collected the data of 29 patients of pre-eclampsia-eclampsia with thrombocytopenia, abnormal peripheral smear and abnormal liver function tests. He presented an article to the 'American Journal of obstetrics and gynaecology' in 1982 and he coined the term HELLP syndrome as he wanted to help educate his fellow clinicians to assist them in recognizing these patients. ${ }^{1}$ Mean maternal age in our study was $27.31 \pm 5.0$ (20-40 years) which is comparable to Fabrein JEF et al $26.2 \pm 7.2$ and with Isler CM et al which was 27.4 \pm 6.5 . $^{9,10}$ Majority of the patients $(56.67 \%)$ in the present study were primigravida. The results were comparable to the study conducted by Sibai BM, the maternal-perinatal outcome associated with the syndrome of hemolysis, elevated liver enzymes and low platelets in severe pre eclampsia-eclampsia. In this group, 52\% were primigravida. They are also comparable to study the spectrum of severe pre-eclampsia, comparative analysis of HELLP syndrome classification by Martin JN et al in which $51 \%$ patients were primigravid. In our study, only $3.3 \%$ patients were $<28$ weeks and $31.7 \%$ patients were $>37$ weeks of gestation at the time of termination. ${ }^{11}$ It is comparable to the study conducted by Vigil P and Gracia D on Pregnancy complicated by pre-eclampsia-eclampsia with HELLP syndrome. ${ }^{8}$ In the above mentioned study, $5.8 \%$ were $<28$ weeks and $40 \%$ patients were $>37$ weeks of gestation. In our study $46.7 \%$ patients were between 32-36 weeks of gestation as compared to Sibai BM et al study in which $40.4 \%$ were in the same group. ${ }^{5}$ 
In the present study, majority of the patients had any one symptom. $91.67 \%$ had headache which was more than in previous studies. $55 \%$ had epigastric pain which is comparable to Martin JN et al. ${ }^{11}$ Visual complains such as blurring of vision was seen in $25 \%$ of patients in the present study comparable to de Gracia VP et al. ${ }^{8}$

In our study, $65 \%$ (42) patients were delivered vaginally. $35 \%$ (21) underwent caesarean section for indications such as fetal distress, abruption placentae, malpresentation, cephalopelvic disproportion etc. Results are comparable to the study conducted by Banoo S. ${ }^{12}$

Table no. 6: comparable results with other studies

\begin{tabular}{|c|c|c|}
\hline Parameter & Other studies & Our study \\
\hline $\begin{array}{l}\text { Mean } \\
\text { maternal age }\end{array}$ & $\begin{array}{l}\text { Fabrein JEF et } \\
\mathrm{al}^{9} 26.2 \pm 7.2\end{array}$ & \multirow{2}{*}{$\begin{array}{l}27.31 \pm 5.0 \\
(20-40 \text { years })\end{array}$} \\
\hline & $\begin{array}{l}\text { Isler CM et al } \\
27.4 \pm 6.5\end{array}$ & \\
\hline \multirow{3}{*}{$\begin{array}{l}\text { Gravida status } \\
\text { Majority } \\
\text { primigravida }\end{array}$} & Baha M Sibai $^{5}$ & \multirow{3}{*}{$56.67 \%$} \\
\hline & $52 \%$ & \\
\hline & $\begin{array}{l}\text { Martin JN et al } \\
51 \%\end{array}$ & \\
\hline $\begin{array}{l}\text { Mode of } \\
\text { delivery }\end{array}$ & Banoo $S^{12}$ & \\
\hline $\begin{array}{l}\text { Vaginal } \\
\text { delivery }\end{array}$ & $60 \%$ & $65 \%$ \\
\hline $\begin{array}{l}\text { Caesarean } \\
\text { section }\end{array}$ & $40 \%$ & $35 \%$ \\
\hline
\end{tabular}

\section{Perinatal outcome}

In our study, there were $68 \%$ live births, out of which 5 died in the early neonatal period. There were $18.3 \%$ of fresh still births comparable to Sibai BM et al which had $19.5 \%$ of still births. ${ }^{5}$ There were $11.7 \%$ IUFD, which were more than Kim YH et al $4.8 \%$ but less than Imir GA et al 18\%). ${ }^{13,14}$ Therefore, the take home babies were 37 .

Perinatal mortality rate $=$

Stillbirth + IUD + Early neonatal deaths births

Total number of births $=38.33 \%$

\section{Total number of births}

The perinatal mortality rate of our study was comparable with Sibai BM et al $(33.3 \%){ }^{5}$ NICU admission was required by $36 \%$ of patients, little more than the study conducted by Sibai BM et al $(28.3 \%){ }^{5}$

\section{Maternal complications}

A Study on maternal outcomes in 442 pregnancies with HELLP syndrome by Sibai BM et al demonstrated that HELLP syndrome is associated with an increased risk of maternal death $(1 \%)$ and increased rates of maternal complications like pulmonary edema 8\% ARF (3\%) DIC
$15 \%$ abruption placentae $9 \%$, liver haemorrhage $1 \%$, ARDS, sepsis and stroke $<1 \%{ }^{3}$ Pregnancies complicated by HELLP syndrome are also associated with increased rates of SSI i.e. surgical site infections and the need for transfusion of blood and blood products. The rate of these complications depend upon the population studied, the laboratory criteria used to establish the diagnosis and on the presence of associated pre-existing medical conditions or obstetric complications. The development of HELLP syndrome in the postpartum period increases the risk of renal failure and pulmonary edema. The presence of abruption placentae increases the risk of DIC, need for blood transfusions, pulmonary edema and renal failure. Patients who have ascites appear to have a higher rate of cardiopulmonary complications.

In our study, $63 \%$ patients had complications associated with HELLP syndrome. $23 \%$ patients had eclampsia with HELLP syndrome. $15 \%$ patients had Hematuria and $7 \%$ had acute kidney injury. In a study conducted by Vigil $\mathrm{P}$ and Gracia D et al, $22 \%$ patients had Hematuria. ${ }^{8}$ In the present study, $10 \%$ had abruption placentae, which is comparable to Imir GA et al $(10.9 \%)$ and Vigil $\mathrm{P}$ and Gracia D et al (12\%). ${ }^{8,14} 3 \%$ patients were in DIC, $3 \%$ had severe anaemia and $2 \%$ had status eclampticus. $7 \%$ (4) patients were transferred to MICU for intensive care management. Early diagnosis, prompt intervention and optimum care resulted in improved clinical and laboratory parameters in all the 4 patients.

\section{CONCLUSION}

HELLP syndrome typically complicates women with preeclampsia. Although the cause of pre-eclampsia is unknown, evidence for its manifestations begins early in pregnancy with covert pathophysiological changes that gain momentum across gestation and eventually become clinically apparent. Thus, early diagnosis, adequate antenatal care and prompt intervention is of utmost importance at the grass root level. Pregnancies complicated by HELLP syndrome, are mostly unpredictable in nature and has predilection for multiorgan involvement. They are associated with substantial maternal and perinatal morbidity and mortality. They result in a clinical spectrum ranging from a simple flu like illness to one of catastrophic deterioration that is life threatening for both mother and fetus. Increased surveillance is therefore required which permits more prompt recognition of ominous changes in blood pressure, critical laboratory findings and clinical signs and symptoms.

With this aim in mind, we have studied 60 cases of HELLP syndrome which elaborates the clinical picture, laboratory parameters and adverse maternal and perinatal outcome associated with it. The study being prospective, all parameters from antenatal detection, clinical signs and symptoms, mode of delivery to maternal and perinatal outcome could be studied. Adverse maternal complications and perinatal outcome, thus, stresses upon 
the need of early ANC registration, routine assessment of $\mathrm{BP}$, albuminuria, weight, regular antenatal follow up and monitoring of clinical symptoms and laboratory parameters. Women should, therefore be counselled regarding the high risk factors, associated clinical symptoms and importance of regular antenatal visits.

Funding: No funding sources Conflict of interest: None declared

Ethical approval: The study was approved by the Institutional Ethics Committee

\section{REFERENCES}

1. Weinstein L. Syndrome of hemolysis, elevated liver enzymes and low platelet count; a severe consequence of hypertension in pregnancy. Am J Obstet Gynecol. 1982;142(2):159-67.

2. Sibai BM, Ramadan MK, Chari RS, Friedman SA. Pregnancies complicated by HELLP syndrome: Subsequent pregnancy outcome and long-term prognosis. Am J Obstet Gynecol. 1995;172:125-9.

3. Sibai BM, Ramadan MK, Usta I, Salama M, Mercer BM, Friedman SA. Maternal morbidity and mortality in 442 pregnancies with HELLP syndrome. Am J Obstet Gynecol. 1993;169(4):1000-6.

4. Geary M. The HELLP syndrome. Br J Obstet Gynecol. 1997;104:887-91.

5. Sibai BM, Taslimi MM, El-Nazer A, Amon E, Mabie BG, Regan GM. Maternal-perinatal outcome associated with the syndrome of hemolysis, elevated liver enzymes and low platelets in sever preeclampsia-eclampsia. Am J Obstet Gynecol. 1986;155(3):501-8.
6. Sibai BM. The HELLP syndrome much ado about nothing? Am J Obstet Gynecol. 1990;162:311-6.

7. Sibai BM, Ramadan MK. Acute renal failure in pregnancies complicated by HELLP syndrome. Am J Obstet Gynecol. 1993;168:1682-90.

8. Vigil P, Gracia D. Pregnancy complicated by preeclampsia-eclampsia with HELLP syndrome. International Journal of Gynecology and Obstetrics. 2001;72:17-23.

9. Javier E, Fonseca M, Clandia C. Dexamethasone treatment does not improve the outcome of woman with HELLP syndrome: a double blind, placebo controlled randomized clinical trail. Am J Obstet Gynecol. 2005;193:1591-8.

10. Isler CM, Rinehart BIL, Terrone DA. Maternal mortality associated with HELLP hemolysis, elevated liver and low platelets syndrome. Am J Obstet Gynecol. 1999;181:924-8.

11. Martin JN, Rinehart BK, May WL, Magann EF, Terrone DA, Blake PG. The spectrum of severe preeclampsia, comparative analysis of HELLP hemolysis, elevated liver enzymes levels and low platelet count syndrome classification. Am J Obstet Gynecol. 1999;180(6):1373-82.

12. Banoo S, Makhdoomi TA, Mir S, Malik J. Incidence of HELLP syndrome in sever pregnancy induced hypertension and its impact on maternal and fetal outcome. JK Practitioner. 2007;14(2):92-4.

13. Kim HY, Sohn YS, Lim JH, Kim EH, Kwon JW, Park YW, et al. Neonatal outcome after preterm delivery in HELLP syndrome. Yonsei Medical Journal. 2006;47(3):393-8.

14. Imir GA, Iclal Ozdemir KOL, Kaygusuz K, Cetin A, Cetin M, Gonullu TGM. Perinatal outcomes in HELLP syndrome. J Turkish-German Gynecol Associ. 2008;9(2):89-93.

Cite this article as: Bang NO, Satia MN, Poonia $\mathrm{S}$. Obstetric and neonatal outcome in pregnancies complicated by hemolysis elevated liver enzymes low platelet count syndrome at a tertiary care centre in India. Int J Reprod Contracept Obstet Gynecol 2016;5:2407-12. 